\title{
Cuerpo y religación en Xavier Zubiri ${ }^{1}$
}

\author{
Eugenia Colomer \\ PONTIFICIA UNIVERSIDAD CATÓLICA DE VALPARAÍSO \\ eugenia.colomer@ucv.cl \\ Ricardo Espinoza \\ PONTIFICIA UNIVERSIDAD CATÓLICA DE VALPARAÍSO \\ respinoz@ucv.cl
}

Resumen: Este artículo indaga sobre los aportes de la filosofía de Zubiri a la experiencia religiosa. El hombre contemporáneo clama por un Dios sentido en la historia, menos doctrinal y más vivenciado. Xavier Zubiri no es ajeno a esta preocupación. Vemos desde sus textos tempranos hasta su pensar maduro "notas" que colaboran a la resolución de tan fundamental problema, y ello, a nuestro juicio, exige una nueva aproximación al tema del cuerpo. Aquí realizamos un recorrido de su obra donde señalamos los hitos de su filosofía para una nueva visión del cuerpo y las repercusiones filosóficas y también teológicas que ello tiene. Esta visión la otorga el cuerpo como principio de actualidad. El cuerpo sentiente y sentido es el "aquî" actual de la religación del hombre al poder de lo real.

Palabras clave: Zubiri, cuerpo, religación, poder de lo real, actualidad

Abstract: This article researches on the contribution of Zubiri's philosophy to religious experience. Contemporary men aspire to a God that is present in history, less doctrinal and more experienced. Xavier Zubiri is not estranged from this concern. We found through his texts, from the early to the mature, thoughts on this fundamental problem and that, from our perspective, call for a new look to the topic of the body. In this article we cover the interior subjects of his work, where we show the milestones of his philosophy for a new vision of the body and the philosophical and theological consequences that it conveys. This view is granted by the body as a principle of actuality. The body that feels and is felt is the current "here" of the man's "rebinding" to the power of the real.

Keywords: Zubiri, body, rebinding, the power of the real, actuality.

$1 \quad$ Este artículo es parte del Proyecto Fondecyt N N 1140973: "Realidad y técnica en Zubiri”. 


\section{INTRODUCCIÓN}

Se ha estudiado el problema de la religación en el pensamiento de Xavier Zubiri desde múltiples enfoques y perspectivas a lo largo de muchas décadas, todos son aportes a la cuestión zubiriana de la religación; sin embargo, nosotros creemos que todavía se puede realizar un nuevo aporte al complejo asunto de la religación si lo miramos desde la última filosofía de Zubiri, esto es, la noología ${ }^{2}$. Es desde ella donde ciertos conceptos cobran un sentido más radical que nos permite releer la religación con nuevos ojos y así podremos ver la riqueza conceptual que hay en este pensamiento zubiriano para hacernos cargo de los temas de hoy en torno al fenómeno religioso. Dos son los puntos fundamentales que surgen de

2 La noología es como se llama, como se sabe, la última etapa filosófica de Xavier Zubiri. No es ni fenomenología ni metafísica. Zubiri mismo nos decía que su investigación pasó desde una Ontología a una estricta Metafísica. La noología es clave en nuestro FONDECYT en torno a la técnica, pues es en ella donde anclamos nuestra investigación y podemos estudiar al articulación originaria que se dan entre intelección (hombre) y lo inteligido (las cosas). Y en esta articulación se produce una aprehensión de lo real por parte del hombre que permite su propia viabilidad como tal. Y en el tema de la religación podemos ver, de modo ejemplar, cómo opera la noología haciendo cargo de lo real mismo como modo existencial que da sentido a la propia realidad humana; realidad que siente lo real desde un más inespecífico que la requiere a ella misma para hacerse cargo de sí y de la totalidad. Zubiri es muy claro en esto: “[...] ¿es lo mismo metafísica y ontología? ¿Es lo mismo realidad y ser? Ya, dentro de la fenomenología, Heidegger atisbó la diferencia entre las cosas y su ser. Con lo cual la metafísica quedaba para él fundada en la ontología. Mis reflexiones siguieron una vía opuesta: el ser se funda en la realidad. La metafísica es el fundamento de la ontología. Lo que la metafísica estudia no es la objetividad [Husserl y su fenomenología] ni el ser [Heidegger y su ontología], sino la realidad en cuanto tal. Desde 1944 mi reflexión constituye una etapa rigurosa metafísica”. X. Zubiri, Naturaleza, Historia, Dios (NHD) (Alianza, Madrid', 1987) 14-15. Así de claro es Zubiri en el Prólogo que realizó para la edición inglesa de NHD (uno de los pocos pasajes que Zubiri habla de sí mismo). Pero su metafísica se abrió a un nuevo modo de pensar, una metafísica fenomenológica, esto es, la noología. La noología se hace cargo de las cosas mismas y no deja nada fuera de ella, es decir, el carácter físico de las cosas reales no es reducido, ni puesto en "epoché", sino que es parte esencial de la propia descripción que se impone en la aprehensión humana. Por eso este carácter físico que mienta no solamente lo real sino radicalmente al acto intelectivo es lo que nuestro pensador llama "noergia", pues si queremos hablar en la terminología del "noein" para expresar la intelección, hay que decir que este "noein" no intelige de modo intencional, sino de modo físico: "[...] el noein es un ergon y por esto su estructura formal es Noergia”. X. Zubiri, Inteligencia y razón (IRA) (Alianza, Madrid, 1983) 94. 
esta mirada noológica a la altura final del pensamiento de Zubiri: inteligencia sentiente y cuerpo, y ambos se recubren por completo.

Respecto a la inteligencia sentiente y su expresión en la Trilogía de la Inteligencia sentiente se ha escrito mucho, pero no del todo vuelto al tema de la religación, por eso, entre otras cosas, la gran categoría noológica de "actualidad"3 se la piensa muy poco en relación con la religación. Y, ni qué decir de las partículas noológicas fundamentales del último Zubiri: "de suyo", "prius", "más", "hacia” y "actualidad”“. Estos elementos tan propios de la noología zubiriana y que permiten tanta riqueza en el análisis, están muy empobrecidos en el problema de la religación. Lo cual no nos permite ver todo el alcance de la religación a problemas contemporáneos de la experiencia religiosa.

Respecto al cuerpo, se observa una ausencia de él en los debates en torno a la dimensión teologal del pensamiento de Zubiri y, en especial,

3 “Actualidad es estar presente desde sí mismo por ser real". X. ZuBIRI, Inteligencia Sentiente/Inteligencia y realidad (IRE) (Alianza, Madrid, 1980) 156. No está de más señalar que el término de "actualidad" tan primordial en el último Zubiri puede ser rastreado en el pensamiento de Heidegger. En el año 1930, Heidegger dictó su gran conferencia De la esencia de la verdad (publicada luego recién en 1943), que inaugura el cambio de orientación de lo más propio de su pensamiento, el giro (Khere), como el mismo Heidegger lo llama, al interior de su reflexión y que nos lleva del hombre al ser mismo (esa radical concepción del ser que no pudo dar a luz en Sein und Zeit de 1927) por medio de la verdad. La verdad entendida en esta nueva posición como Lichtung y Unverborgenheit (idea que está presente en todo el pensamiento heideggeriano posterior a 1927) trae la idea de que son las cosas las que nos permiten juzgar acerca de ellas. Nuestros juicios serán "verdaderos" porque de antaño la cosa "verdadea" ante el hombre está presente ante él. La cosa porque se da como "presente" es porque puede ser "re-presentada" en el juicio. Esto es, la verdad como conformidad o adecuación reposa en algo anterior que la constituye; y esto es propio de la cosa en cuanto a su carácter de presentarse. Véase, por ejemplo, M. HeIDEgGer, "II. La posibilidad intrínseca de la coincidencia”, en ¿Qué es metafísica? Y otros ensayos (Fausto, Buenos Aires, 1996) 114-116. Aquí ya está incoada la idea zubiriana de la actualidad. En el término alemán "stellen" con todas sus variantes ya podemos encontrar indicios de la actualidad como "estar presente en cuanto estar".

4 Véase en detalle, para analizar los elementos noológicos del último Zubiri: R. EsPINOZA, "Realidad y «de suyo" como lo otro que nos apropia”, en Realidad y ser en Zubiri (Comares, Granada, 2013) 127-267. En este capítulo del libro se analizan en detalle los elementos de: "de suyo", "prius", "más", "hacia” y "actualidad". Estos elementos son fundamentales para comprender cómo el carácter técnico de la propia inteligencia sentiente opera desde el inicio en su articulación con lo real. 
en lo que respecta al problema de la religación. Es como si la dimensión teologal no estuviera encarnada en el hombre, ya como individuo, ya como sociedad, ya como historia ${ }^{5}$. Y creemos que esto es un grave error. Más aún cuando la concepción del cuerpo en Zubiri está presente durante toda su vida y nace de modo explícito en ámbitos teológicos ya por los años 20 y se profundiza en los $30^{6}$. Mucho antes incluso de la publicación de Naturaleza, Historia, Dios ${ }^{7}$. Y esta concepción zubiriana en torno al cuerpo (y con ello de la materia, de la naturaleza, etc.) va adquiriendo precisiones fundamentales a lo largo de décadas de investigación que le permitirán construir ya una filosofía como una teología muy

5 Véase en detalle, X. Zubiri, Tres dimensiones del ser humano: individual, social, histórica (TDSH) (Alianza, Madrid, 2006). En este libro se indica claramente el carácter físico del hombre que se despliega en tres dimensiones articuladas las unas con las otras. Es por esta razón, Zubiri puede señalar tajantemente lo siguiente respecto del alma en 1974 y con ello a la vez del cuerpo, el carácter físico mismo de la realidad humana: "Algunos se preguntarán qué es lo que pasa con las almas después de muertos. No sé lo que pasa. Pero no es de fe que sobreviva”, 7.

6 "[...] Zubiri antes de la publicación (1944) de su primer libro Naturaleza, Historia Dios ya pensaba desde el problema mismo de la unidad del hombre y siempre veía que el hombre es corporal y desde ese carácter natural deberíamos pensar su trascendencia, su alma, etc. Se tenía que mostrar más que una dialéctica entre cuerpo y alma, más que un alma sustancial inmortal que está «dentro» del cuerpo material y corruptible, una cierta unidad de "emergencia» del alma desde el cuerpo, pero no sabía del todo cómo pensarlo sin las herramientas conceptuales de la filosofía”. P. Ascorra-R. Espinoza, "Cuerpo y alma en Zubiri... Un problema filosófico-teológico”, en Pensamiento 67/254 (2011) 1064. Zubiri veía una forma del cuerpo distinta, desde cierta teología y filosofía griega, esto es, entender el cuerpo como "sôma", como presencia real decía entonces (más adelante será más claro y será el principio de actualidad mismo de la naturaleza, de la materia), terminología cercana a la de Heidegger. Pero antes, en la década del 30, en torno al cuerpo de Cristo se permitía decir lo siguiente: "En el cuerpo glorioso de Cristo está la raíz de una glorificación que será comunicada al hombre y a la creación natural entera. Quizá sirva para este problema la distinción entre sôma y sárx [...] El sôma expresa la presencia real y circunscriptiva de un ser distenso en el espacio. Lo que llamamos materia es el ente que tiene este modo de ser somático. En el hombre esta materia es sárx, carne". X. Zubiri, Naturaleza, Historia, Dios (NHD) (Alianza, Madrid, 2004) 516-517. Este ensayo surge de un curso dado por Zubiri en la Universidad de Madrid titulado Helenismo y Cristianismo en el semestre de invierno de 1934-1935 (este curso recién ahora ha sido publicado en X. ZuBiri, Cursos universitarios. Volumen IV (CU 4) (Alianza, Madrid, 2014) y profundizado durante los años 1937-1939 en el Círculo de Estudios del Foyer internacional des étudiants catholiques de la Ciudad Universitaria de París.

7 La primera edición fue de Editora Nacional, Madrid, 1944. 
distintas a la clásica racionalista europea ${ }^{8}$. El pensamiento de Zubiri se mueve en lo físico de la realidad. Y si añadimos el desarrollo noológico de su pensamiento al final de su vida, el concepto de cuerpo adquiere una dimensión fundamental para tratar el problema de la religación. Y de esto daremos ciertos bosquejos fundamentales en este artículo.

\section{EL PODER DE LO REAL}

Un tema fundamental para comprender de modo acabado la religación es el poder de lo real. El poder de lo real es un momento básico del "de suyo" . La realidad es poderosa en tanto tiene "primacía" sobre el conte-

8 Estos textos son fundamentales para entender en un sentido amplio el problema del cuerpo en Zubiri. La trilogía de Inteligencia Sentiente de X. Zubiri (1980-1983). Y también del autor son fundamentales: El hombre y Dios (HD) (Alianza, Madrid, 1998). Sobre el Hombre (SH) (Alianza, Madrid, 1998). Sobre el problema de la filosofia y otros escritos (1932-1944) (SPFO) (Alianza, Madrid, 2002). Naturaleza, Historia, Dios (NHD) (Alianza, Madrid, 2004). Tres dimensiones del ser humano: individual, social, histórica (TDSH) (Alianza, Madrid, 2006). "El hombre y su cuerpo" (HC), en Escritos Menores (1953-1983) (EM) (Alianza, Madrid, 2006). Sobre la esencia (SE) (Alianza, Madrid, 2008). En relación a la recepción del pensamiento de Xavier Zubiri respecto del tema del cuerpo es posible confrontar los estudios de P. LAín ENTRALGo, El cuerpo humano. Teoría actual (Espasa-Universidad, Madrid, 1989); Cuerpo y alma. Estructura dinámica del cuerpo humano (Espasa-Calpe, Madrid, 1991); Alma, cuerpo y persona (Galaxia Gutenberg, Madrid, 1995). También hay artículos recientes fundamentales para el tema del cuerpo en Zubiri. Por ejemplo, P. Ascorra-R. EspinozA, "Cuerpo y alma en Zubiri... Un problema filosófico-teológico", en Pensamiento 67-254 (2011) 1061-1075; R. EspinOza y otros, "Nietzsche y la concepción de Naturaleza como Cuerpo", en Alpha 34 (2012) 95-116. R. EspinOZA Y OTROS, "Realidad y actualidad. Una primera aproximación al tema del cuerpo", Arbor, 189-17(760) 1-14, disponible en: http://dx.doi.org/10.3989/arbor.2013.760n2003;

R. EsPinOza - P. Ascorra, "Heidegger y Zubiri. Y «el problema de Dios»", en Veritas 27 (2012) 9-33. Otros textos fundamentales son: M. É Boismard, "Nuestra victoria sobre la muerte según la Biblia”, en Concilium 105(1975) 256-260. Entrevista a M. É. Boismard, en Revue de L'au-dela 116 (2007), disponible en: http://www.menssana. fr/elements/116/116rencontre.pdf

Estos textos son prioritarios para trabajar el problema del cuerpo y además nos permiten, por una parte, entender en el hombre mismo la dimensión técnica de la inteligencia sentiente en su articulación con las cosas y, por otra parte, sumergirnos en una religación encarnada. Y esta religación se mueve en planos de aprehensión primordial, logos y razón de una inteligencia sentiente que aprehende técnicamente lo real, incluso la fundamentalidad.

9 “[...] lo sentido se me presenta como algo que tiene una especie de fuero interno propio: es caliente, es frío, es pesado, etc., de suyo. No se trata de que el contenido 
nido de cada cosa real; esta primacía mienta el elemento noológico del "prius"10. El carácter real, en tanto "prius", se impone sobre el contenido y lo "reifica", cuestión inexorable para el hombre, quien nunca aprehende puros contenidos sino siempre contenidos reales. "La poderosidad,

sea propio de un sujeto que esté por debajo o por detrás de lo propiamente sentido, sino que de suyo significa que eso que es el contenido de la impresión tiene ese carácter formal propio. Pues bien, este carácter de de suyo es lo que llamo realidad. Cada cosa es real precisa y formalmente por ser de suyo aquello que ella es en impresión. Ser real significa pura y simplemente ser de por sí, ser de suyo aquello que nos presenta en la impresión. El de suyo, pues, lo que constituye la realidad en cuanto tal”. X. Zubiri, Espacio, Tiempo, Materia (ETM) (Alianza, Madrid, 2008) 153. Véase, R. EspinozA, "I. Realidad y "De suyo»", en Realidad y ser..., 129148. Véase, también a Heidegger. El filósofo alemán también piensa algo similar a comienzos de los años 30, en pleno "giro" de su pensamiento. Hay un texto muy importante en esta misma línea donde Heidegger explica las "anticipaciones de la percepción” (A 143, B 182) en el Capítulo I (El esquematismo de los conceptos puros del entendimiento) del Libro Segundo (Analitica de los principios) de la Analítica Trascendental de la Crítica de la razón pura de Kant; en este texto Heidegger hace la interpretación fenomenológica de la importancia radical de que Kant anticipe lo real en la percepción misma como condición de posibilidad de la objetividad del objeto. M. Heidegger, La pregunta por la cosa (Alfa, Buenos Aires, 1975) 193.

10 "Realidad es el modo de ser «en propio», dentro de la aprehensión misma. «En propio» significa que pertenece a lo aprehendido, por tanto, aún antes de la aprehensión misma (prius)”. X. ZuBIRI, Inteligencia y logos (IL) (Alianza, Madrid, 1982) 12-13. Véase, el estudio detallado acerca del "prius": R. EspinOzA, "Realidad y "Prius»", en Realidad y ser..., 148-181. Para entender mejor este elemento noológico: "No se trata de ir tras lo físico mismo, o sea, tras el emerger mismo de lo real qua real que se nos impone inexorablemente; esto es un modo muy adecuado para comprender acabadamente lo que luego la filosofía francesa, italiana o alemana ha llamado simplemente Acontecimiento (Événement, Evento. Ereignis, respectivamente). Porque tras este emerger físico no se esconde nada y esto es fundamental no olvidarlo (la misma aprehensión primordial debe ser vista de esta forma)". Ibíd., 151. Como dice Diego Gracia de forma muy clara: "Lo aprehendido se me actualiza como "de suyo». El "de suyo" no es el «en sí» del realismo ingenuo, ni el «en mí» del idealismo, también ingenuo. El «de suyo» es realidad, pero realidad en la aprehensión, no allende ella. A pesar de lo cual, en el «de suyo" hay un momento que Zubiri llama de "prius». Se ha discutido mucho lo que puede significar ese término. Espinoza Lolas da una explicación que a mí me parece definitiva. En la aprehensión la iniciativa no la toma la conciencia, como sucedía en Husserl, sino que es la propia realidad, el propio "de suyo» el que sale por sus fueros y se impone. Lo originario no es ningún tipo de "posición", como sucedía en el idealismo, sino la «imposición» de la propia realidad. Eso es lo que Zubiri llama "fuerza de imposición»". D. Gracia, "Prólogo", en R. Espinoza, Realidad y tiempo (Comares, Granada, 2006) XIX. 
concebida explícita y formalmente como real, no es dominancia simplemente, sino que es dominancia de lo real en cuanto real" 11 . Junto con la primacía de la realidad en tanto "de suyo" como "prius", la realidad se expresa en tanto "más"; esto es, en su carácter abierto como "prius" por ser lo que es "de suyo" y que excede en respectividad. Por esta razón, las cosas son aprehendidas no solo como un otro en radical alteridad (como "de suyo"), sino que hay una apertura en excedencia; al sentir lo real como "de suyo" lo sentimos como abierto y entramos en el dominio de la realidad respectivamente abierta:

"Realidad es «más» que las cosas reales, pero es «más» en ellas mismas. Y justo esto es dominar: ser "más» pero en la cosa misma; «la» realidad como realidad es dominante en esta cosa, en cada cosa real [...]. Pues bien, este dominio es lo que debe llamarse poder. Dominar es ser «más», es tener poder. Aquí, poder no significa ser una causa [...]. El momento de realidad domina sobre la talidad, tiene poder. Por esto es «más» que la talidad. Y este «más» es justo un aspecto de la respectividad constitutiva de la realidad en cuanto realidad"12.

Las cosas vehiculan el poder de lo real, y poder es dominancia que se puede verificar en dos líneas: dominancia de la cosa real en tanto poderosidad y dominancia del poder de lo real en tanto real ${ }^{13}$. El poder de lo real en tanto real no trata solamente del poder de lo real de las cosas reales, sino del momento mismo de realidad de ellas; su mero carácter real. Es una dominancia de tipo funcional, ejerce la función de fundamentalidad. La fundamentalidad se actualiza como funcional en las cosas reales en tanto que poder. Las cosas reales quedan trabadas unas con otras en esa actualización funcional. Digamos de inicio que no se trata de causalidad, la causalidad se comprende desde otra visión de la realidad (una visión metafísica y nunca noológica) ${ }^{14}$, aquí estamos en un momento anterior a cualquier causa (además toda causa siempre es una construcción metafí-

\footnotetext{
HD 39.

HD 94.

Cfr. HD 95-97.

14 Un texto donde precisa la distinción entre ambas visiones es el siguiente: "No tenemos que tratar directamente de lo real en cuanto real; este sería un problema metafísico. [En la noología] Nos preguntamos por lo real en y por sí mismo, pero tan solo en cuanto es aprehendido en aprehensión primordial de realidad". IL 348. La noología se ocupa del análisis de la realidad en tanto que actualizada en la aprehensión (y aquí está su modo técnico), la metafísica en cambio, atiende a la realidad como fundamentalidad allende la aprehensión.
} 
sica), estamos en el momento constituyente del "de suyo" mismo, y bajo una mirada constructa ${ }^{15}$. La realidad por este momento de poder tiene carácter fundante. El hombre aprehende las cosas como siendo ellas "más" que su contenido (esto es fundamental porque deja al hombre en una forma de realidad de carácter técnico), pero no olvidemos que a una se actualizan las cosas y nuestra propia realidad, por tanto la dominancia del poder de lo real la ejerce la realidad sobre las cosas y sobre el hombre que las aprehende, por tanto la realidad en tanto que funciona como fundante ejerce un poder sobre nosotros. Y de allí toda la experiencia humana y el despliegue de la cultura y. por tanto, el logos y la razón.

El poder de lo real va adquiriendo cada vez mayor importancia y se observa cómo va desplazando otros términos en la propia filosofía de Zubiri. Respecto a las fuentes inspiradoras del mismo las podemos recoger, desde el pensamiento heideggeriano y la teología de los Padres griegos $^{16}$. El hombre es el único ser que está continuamente realizándo-

15 "Las cosas están constituidas por «notas» [...] toda nota lo es por estar articulada con las demás [...] El «de» le pertenece en forma intrínsecamente. Es lo que inspirándome en las leguas semitas llamo carácter o estado "constructo» de toda nota”. SH 44. Y visto desde un modo más radical de las cosas mismas, Zubiri piensa que el carácter constructo, su unidad: "[...] es la unidad estructural que consiste en ser un sistema "constructo", esto es, un sistema en que cada una de sus notas no tiene realidad propia de nota más que siendo intrínseca y formalmente «de» las demás. El ser sistema constructo es la esencia misma de lo real en cuanto real. De ahí su función radical”. IRA 112. Inteligencia y razón que es el último libro de la Trilogía (y escrito por Zubiri, murió el mismo año de su presentación), es el libro que mienta lo metafísico de antaño (Sobre la esencia de 1962) a la altura de una mirada noológica.

16 Zubiri veía una forma del cuerpo distinta desde cierta teología y filosofía griega, esto es, entender el cuerpo como "soma" decía en este Curso: "Las cosas que tienen materia son unas, como todo ente, por su principio formal, pero aquí se introduce una nueva dimensión. En estos seres la forma está recibida en un sujeto caracterizado por una interna exterioridad; la alteridad es aquí exterioridad; la distinción, distancia. En consecuencia, la forma se extiende en el tiempo y en el espacio. Aquí, tiempo y espacio no son entidades geométricas, sino algo que afecta a la acción formal del ser, haciendo de ella no simplemente una tensión sino una ex-tensión y una dis-tensión en sentido activo: la espaciosidad y la temporeidad, desde las que se recoge y se repliega el ser en interna unidad. Tiempo y espacio son así el ámbito en que están circunscritas las posibilidades de la acción en que el ser consiste. Por esto hay muchos modos distintos de estar en el tiempo y en el espacio. No insisto más aquí. Estas cosas materiales son de tres órdenes [...] En primer lugar, los cuerpos (sôma). Soma no significa en primera línea la simple 
se y en su propia realización personal experimenta el poder de lo real. La filosofía ha ido borrando de su ámbito la idea de poder, es una idea fundamental como punto de partida, según Zubiri, para acceder a qué sea ulteriormente ese fundamento (extra-mundanamente). El poder de lo real se apodera del hombre y le impele a realizarse, entendiendo que lo dominante tiene un carácter físico. Recordemos que físico es, para Zubiri, sinónimo de real ${ }^{17}$.

El mismo Zubiri a lo largo de las decenas de páginas de la Trilogía de Inteligencia sentiente va precisando ese carácter de lo real como físico (contra todo tipo de racionalismo, idealismo y fenomenologías euro-

materia pasiva e inerte, sino la manera cómo la unidad formal del ser tiene realidad en los límites circunscriptos y definitivos que le impone su «extensión». Lo que llamamos materia es el ente somático. En rigor hay que entender la materia desde el sôma, y no el sôma desde la materia". NHD 516-517. "Este texto está en la línea más propia que luego Boisrmard desarrollará. Pues la concepción de «carne» semita tiene esa idea de la sárx griega; incluso se utiliza tal palabra griega en el prólogo de San Juan 14. Y esta carne implica a la vez cuerpo y alma, un todo, el hombre sin más". "Cuerpo y alma en Zubiri... un problema teológico-filosófico" 10641065. Boismard lo indica muy claramente de la siguiente manera: "Y el Verbo se hizo carne. Hemos visto más arriba lo que había que entender por este término «carne». No es solamente el cuerpo del hombre, independiente del alma. Según una manera de hablar en los libros sagrados, la carne designa al hombre entero, cuerpo y alma, pero considerado en su debilidad inherente al hecho de estar destinado a la corrupción”. M. É. Boismard, El prólogo de San Juan (Fax, Madrid, 1967) 81.

17 Zubiri ya en Sobre la esencia de 1962, ya en la Trilogía de Inteligencia sentiente de 1980-1983, comienza realizando una determinación del vocablo "físico". En tal vocablo ve arraigada su idea de realidad en su carácter más propio. En ambos textos se dice casi lo mismo, pero lo que se dice es vital para el desarrollo de las ideas y marca la diferencia con sus etapas anteriores filosóficas: fenomenológica y ontológica (incluso metafísica). Es el rasgo físico el que constituye al noema y al sentido (al fenómeno sin más); esto se indica de la siguiente manera en Inteligencia sentiente: "Físico es el vocablo originario y antiguo para designar algo que no es meramente conceptivo sino real. Se opone por esto a lo meramente intencional, esto es a lo que consiste tan solo en ser término del darse cuenta”. IRE 22. En el texto de antaño de Sobre la esencia queda muy clara la relación entre inteligencia y realidad a través de las notas como físicas: "[...] el acto mismo de inteligir es algo físico. Aquí, pues, lo «físico» se contrapone a lo «intencional» [una vez más la crítica a Husserl]. Y de aquí "físico» vino a ser sinónimo de «real», en el sentido estricto de este vocablo. El peso y el color de un manzano son físicamente distintos; son, en efecto, dos notas reales, cada una por su lado, y que contribuyen a «integrar» la realidad de aquel [...] Físico y real, en sentido estricto, son sinónimos”. SE 12. 
peas) hasta concebirlo como un mero "estar"18 o mejor aún como la "actualidad"19 por excelencia. La actualidad mienta en sentido estricto la misma realidad pero en su carácter real, esto es, "reificante". O sea, es la realidad en su estar presentándose en tanto que "estar" presentándose. Por esto, actualidad como elemento noológico es central en el último Zubiri, pues vehicula la misma realidad en respectividad e indica la realidad como anterior a cualquier connotación metafísica o de relatos que se relacionan. La actualidad es en sí misma el mejor nombre para la realidad al final del recorrido de Zubiri. Renueva desde dentro el concepto de realidad y lo deja operativo en el horizonte noológico. Y por eso, la realidad como actualidad se vuelve en "el" elemento noológico por excelencia que recorre y da sentido a toda la Trilogía de Inteligencia sentiente ${ }^{20}$. De allí que realidad como formalidad y actualidad comprendida como ese "estar" presente impositivo mientan lo mismo, aquel

18 "El «estar» en qué consiste físicamente el acto intelectivo es un «estar» en que yo estoy «con» la cosa y «en» la cosa (no «de» la cosa), y en que la cosa está «quedando» en la intelección. La intelección como acto no es formalmente intencional. Es un físico «estar». La unidad de este acto de «estar» en tanto que acto es lo que constituye la aprehensión". IRE 23.

19 Zubiri es muy tajante en Inteligencia y logos. Y da una precisión radical al mismo término real (que ha sido siempre entendido como físico), que sea física quiere decir que lo real es un "estar" en actualidad, esto es, un estar siendo en actualidad. Las cosas quedan como reales mienta que quedan como físicas y esto significa precisamente que quedan siendo en actualidad. Las cosas quedan como estando en presencia, en cuanto que están. Por esto en este libro de 1982 ya Zubiri no dice formalidad de realidad sino simplemente formalidad de actualidad: "Lo aprehendido queda en la aprehensión según su formalidad. Es lo que he llamado actualidad. Actualidad no es presencia, sino un estar en presencia". IL 102.

20 Para un estudio detallado en torno a la actualidad, véase, R. EsPinOzA, "Realidad y Actualidad", en Realidad y ser..., 245.267. Y no hay que olvidar algo fundamental para nuestro tema de investigación en este artículo, que como dice Zubiri: “[...] la actualidad... no añade ninguna nota física a lo real”. IRE, 230. No podemos nunca dejar de lado que en el término actualidad se está pensando de forma radical la realidad y de un modo noológico, pues se la entiende como actualidad, esto es, un estar presente en cuanto "está" presente: “[...] el «estar» presente en cuanto estar: es lo real «estando" presente en y por sí mismo como real”. IL, 350-351. El mismo Pedro Cerezo lo explica de forma muy nítida lo que es la actualidad: "la actualización se opone... a la mera representación (Vor-stellung). Es la presencia efectiva de algo en su manifestación desde sí y por sí en y para la inteligencia, poniendo a esta en su acto propio de aprehender". P. CEREzo., "El hombre, animal de realidades", en VV.AA., La filosofía de Zubiri en el contexto de la crisis europea (Universidad de Santiago de Compostela, Santiago de Compostela, 1996) 62. 
"coestar" de la inteligencia y lo real nos deja absolutamente retenidos, poseídos y arrastrados por el carácter mismo de realidad de las cosas reales al ser sentidas en impresión. Por tanto, la imposición y la impresión quedan totalmente articuladas entre sí en el vocablo "estar" que mienta lo propio de lo "físico" en lo que consiste la formalidad de realidad" Por este carácter físico las cosas nos "quedan" impuestas de una "forma" determinada en nuestra aprehensión impresión. La experiencia del poder de lo real es corporal, en tanto cuerpo sentiente, sentido y realizado como cuerpo personal, de hecho si no sintiéramos intelectivamente no podríamos, luego, acceder a aquella realidad-fundamento que siempre se nos plantea problemáticamente.

Este momento de apoderamiento no es un momento posterior a mi realidad personal, sino constitutivo de ella: "El poder se apodera de aquello sobre lo que domina. Dominancia es apoderamiento. El poder de lo real se apodera de mí. Y gracias a este apoderamiento es como me hago persona. La realidad es fundante de una realidad personal por apoderamiento según el poder de lo real”22. Entonces, ¿qué debemos entender por fundamentalidad? Como muchas veces ante un concepto que tiene, por la tradición, una fuerte carga semántica, nuestro autor comienza derribando los prejuicios que aquel concepto mismo trae. Fundamentalidad es asociada no solo por la filosofía, sino por el sentido común al concepto de causa, de hecho muchas veces se usan indistintamente fundamento y causa. Pero aquí fundamentalidad no es causa, ni entendida como producción en sentido aristotélico, ni tampoco como sucesión de acuerdo a la crítica que realiza Hume a la causa como producción ${ }^{23}$. El

21 Cfr. R. Espinoza, “Deleuze y Zubiri...en torno a una lógica de la impresión”, en Contrastes XII (2007) 93-112.

22 HD 95.

23 Cfr. HD 92-93. Zubiri afirma que la filosofía moderna ha hecho una reducción de la causa aristotélica a la causalidad eficiente. Aristóteles nunca definió qué sea la causa, simplemente afirma que es un "modo de principio" y "principio consiste en que algo proceda de otro" y de inmediato presenta las maneras de causación existen en el Universo, en la Realidad, una de ellas es la causalidad eficiente. "[...] la palabra causa ha sufrido una restricción importante en el curso de la historia, en la cual el concepto de causa material y formal, en tanto que causas es más que discutible, y prácticamente ha desaparecido. La finalidad se estima que es una cosa propia y exclusiva de las acciones humanas. Y, por consiguiente, ha quedado reducido el problema de la causalidad al problema de la causa eficiente". X. ZuBIRI, Estructura dinámica de la realidad (EDR) (Alianza, Madrid, 1989) 74. 
poder que vehiculan las cosas, en tanto reales, ejerce sobre el hombre la función de fundamentarlo. Fundamentalidad es funcionalidad. El ser humano está fundado en la realidad como algo último, posibilitante e impelente, gracias a la fuerza de imposición y al poder de la realidad que hace que el hombre inexorablemente deba realizarse de un modo u de otro (se juega su propia realidad en ello; de allí su dimensión técnica para generar, por ejemplo, todo tipo de utensilios o realidades para ser), pues bien, ese apoderamiento es la religación.

\section{LA RELIGACIÓN Y EL PODER DE LO REAL}

El apoderamiento acontece ligándonos al poder de lo real para ser relativamente absolutos ${ }^{24}$. Esta peculiar ligadura es justo religación. Religados al poder de lo real es como estamos apoyados en él para ser relativamente absolutos y esto es un hecho perfectamente constatable según nuestro autor, por ello se actualiza en la aprehensión primordial de realidad, previo a cualquier afirmación o conceptuación, además es un hecho integral porque afecta al hombre en toda su realidad; pero es más grave aún, de él pende nuestra propia realidad personal. Todo acto humano y práctica humana es libre, pues está formalmente "absuelta" (obviamente no estamos hablando de rasgos estimúlicos tipos de lo fisiológico humano). Y de aquí nacen las dimensiones estética, ética, política, teologal, etc., del hombre. La realidad humana no está condicionada a meramente ser un sistema sustantivo de notas coherentes que están siendo en el "aquí" cósmico, sino que es una realidad absuelta (libre) en el mundo; libre para realizar su propia vida puesto que "de suyo" el hombre se tiene físicamente a "sí mismo", por eso, dicho con otros términos, es consciente, reflexiona y por ello se dice desde hace siglos que el hombre es "espiritual”. Los alemanes utilizan el término unbedingt (que se traduce por incondicionado ${ }^{25}$ ) para referirse a este carácter absuelto de la realidad

24 "Es que el hombre no solo tiene realidad, sino que es una realidad formalmente «suya», en tanto que realidad. Su carácter de realidad es «suidad». Es lo que, a mi modo de ver, constituye la razón formal de persona. El hombre no solo es real, sino que es «su» realidad. Por tanto, es real «frente a» toda otra realidad que no sea la suya. En este sentido, cada persona, por así decirlo, está «suelta» de toda otra realidad: es «ab-soluta» (...) Pero solo relativamente absoluta, porque este carácter de absoluto es un carácter cobrado". HD 7.

25 Félix Duque, respecto al concepto de lo incondicionado [unbedingt] cita a Schelling: "Llamamos bedingen (condicionar) al acto por el cual algo deviene Ding 
humana; sin embargo, lo que indica el término es el carácter no "cósico", no empírico del hombre (Zubiri diría que no es meramente "talitativo" o Heidegger habla de lo existencial para distinguirlo de lo óntico ${ }^{26}$ ). Lo "ab-suelto" indica el rasgo propio de la "suidad" humana en vistas a todas las otras realidades. Por esto se dice que el hombre es "absoluto" (en alguna medida casi como Dios). Lo libre por excelencia, el "aquí" somático abierto al mundo, pero siempre desde un "aquî" y, por ende, traspasado de lo empírico, cósico, talitativo, óntico para realizar su absolutez. El hombre como realidad absoluta lo es siempre de modo relativo; es un ser histórico. Su "aquí" corporal ${ }^{27}$ lo inserta en el movimiento (en el devenir) cósmico y en ello nace precisamente el carácter histórico tan propiamente humano; y así ese devenir se expresa, en definitiva, en las dimensiones estética, ética, política, teologal, etc., del hombre.

Zubiri describe tres caracteres de la religación: experiencial, manifestativo y enigmático. Respecto al carácter experiencial: "el hombre tiene experiencia de lo que es el poder de lo real y, por consiguiente, una experiencia de lo que es la realidad misma como poder. La religación tiene, pues, carácter experiencial'28. La experiencia es un momento del

(cosa)[...] lo cual es tanto como decir que nada puede ser puesto por sí mismo como Ding ([cosa]) [...] Así que Unbendingt (incondicionado) es aquello que de ningún modo puede hacerse Ding (cosa)". Vom Ich als Prinzip der Philosophie oder über das Unbedingte im menschlichen Wissen (1795), I/I, 166. F. DuQUE, Historia de la Filosofía Moderna (Akal, Madrid, 1998) 258.

26 "La «esencia» del Dasein consiste en su existencia. Los caracteres destacables en este ente no son, por consiguiente, "propiedades» que estén ahí de un ente que está-ahí con tal o cual aspecto, sino siempre maneras posibles de ser posibles para él y solo eso". M. Heidegger, Ser y tiempo (Editorial Universitaria, Santiago, 2002) 67.

27 “Lo real «está» en medio de cosas reales (cosmos), pero queda en «la» realidad de ellas (mundo). Entonces, hay una doble consideración de la actualidad. Por una parte, la talitativa o cósmica en que lo real está como un "estar aquí» y no en abstracto ni en cualquier parte, sino "aquí»; el cuerpo es fundamental en esta dimensión para entender la actualidad en su realización efectiva y en ello lo somático embellece, estructura, da unidad, organiza y diferencia al cosmos entero desde el hombre. El cuerpo, en una primera afirmación noológica, es el "estar aquí» radical de lo real humano en la realidad, por ser real en tanto fuerza impositiva y de arrastre". R. EsPinOza y OTROS, "Realidad y actualidad..., 7. "Por el hecho de ser talitativamente respectivo, lo real no solo es cósmicamente respectivo "a» otras realidades cósmicas, sino que está presente «en» el cosmos. El «en» no es ahora el mundo sino el cosmos. El «aquí» es entonces estar presente "en» la realidad cósmica [...] actualidad es un estar «aquí», es un estar «en» el cosmos". ETM 371.

28 HD 100. 
método de la marcha intelectiva de la razón, pero Zubiri pone la religación como un hecho de la aprehensión primordial de realidad, entonces, ¿cómo entender esta afirmación? Diego Gracia no pasa por alto esta dificultad y lo resuelve leyendo esta afirmación realizada en el texto del El hombre y Dios desde Inteligencia sentiente, argumentando que "sería un error echar en olvido que el conjunto de la obra, salvo muy contadas páginas, fue redactado con varios años de antelación al tríptico sobre la inteligencia”29. Gracia afirma enfáticamente que la religación está dada en la aprehensión primordial de realidad y que la "experiencia" de la religación acontece como momento del despliegue racional, de allí que la religación es anterior a toda experiencia y la funda. Sin embargo, la afirmación del carácter experiencial de la religación, Zubiri la expone en el capítulo tres del texto que el editor de la última edición de El hombre y Dios (editado por Esteban Vargas el año 2013), titula "Redacción final”, texto revisado por Zubiri en 1983. Una posibilidad de solución sería apoyarse en la unidad de la intelección, donde nuestro autor afirma al respecto que los modos de intelección no son una mera sucesión, sino tienen una unidad radical, donde cada modo está incoactiva y formalmente en los otros. "Cada modo no solamente despliega al anterior y es incoactivamente el siguiente, sino cada modo se incluye formalmente en el siguiente [...] entonces es claro que en virtud de esta inclusión, el modo anterior queda cualificado por el siguiente" ${ }^{30}$.

Para exponer el carácter experiencial de la religación nos remite a la aclaración del concepto experiencia, tal como lo trató en Inteligencia y razón ${ }^{31}$

29 D. Gracia, Voluntad de verdad. Para leer a Zubiri (Labor, Barcelona, 1986) 217. Respecto al "canon hermenéutico" que propone Diego Gracia, Andrés Torres Queiruga presenta algún reparo: "Bien sé que lo que Diego Gracia ha llamado el "canon hermenéutico" de todos sus escritos debe ser tenido en cuenta. Pero creo también que su función es más bien de control que propiamente heurística, pues, como decía Newman, la lógica abstracta puede servir para aclarar -a veces también para complicar- y vigilar la corrección del discurso, pero viene siempre después de que la lógica viva y concreta ha hecho ya su camino. De hecho, puede afirmarse que todos los problemas tratados en este libro fueron elaborados por Zubiri, no solo con independencia de este esquema, sino antes de haberlo contenido en su detalle”. A. Torres Queiruga, Filosofía de la religión en Xavier Zubiri (Colección Diáspora Editorial Tirant lo Blanch, Valencia, 2005) 18.

30 IRA 323.

31 IRA 223-228. 
donde lo radical en ella consiste en hacer probación física de la realidad, en este caso del poder de lo real.

"El hombre, haciendo religadamente su propia persona, está haciendo la probación física de lo que es el poder de lo real. Es la probación de la inserción de la ultimidad, de la posibilitación y de la impelencia en mi propia realidad. Al hacerme realidad personal soy, pues, una experiencia del poder de lo real y, por tanto, de «la» realidad misma. Esta probación se va ejercitando por todas las rutas individuales, sociales e históricas. Desde este punto de vista, toda diversidad de los individuos en el curso de su vida, sus constitutivos sociales y su despliegue histórico a la altura de los tiempos son una fabulosa, una gigantesca experiencia del poder de lo real" ${ }^{\prime 2}$.

La experiencia del poder de lo real, en tanto probación en la propia construcción personal, rea-ctualiza el poder de lo real primordialmente aprehendido, es el poder de lo real el que determina la marcha que desemboca en la probación física del mismo poder en la realización de la propia persona, pero que al r-actualizarse allí se ve determinado. Se trataría de una aprehensión comprensiva corporalizante no solo de su dimensión individual, sino también social e histórica en su carácter determinante y determinado ${ }^{33}$. Digamos por el momento solo esto ya que más adelante trataremos con detención este carácter.

La religación presenta también un carácter manifestativo y enigmático. El poder de lo real se manifiesta apoderándose de nosotros e imponiéndonos que adoptemos una forma determinada de realidad, es el poder de lo real que ostenta su carácter religante.

32 HD 101.

33 "El cuerpo es la actualidad misma del hombre, es su estar siendo en el cosmos con toda su materialidad individual, social e histórica. Es un cuerpo de suyo propio, entre otros cuerpos, ya del modo filético, ya del modo social y es, además, un cuerpo que se entrega de generación en generación como ciertas capacidades de actualidad, es decir, modos de ser físicamente en el cosmos y de estar abiertos al mundo, es la historia entendida de un modo corporal. Y allí, en definitiva, estaría el carácter teologal corporal que integra todas estas otras dimensiones humanas como un cierta religación en comunidad de unos con otros en vistas a algo que los supera y les da un sentido, un cierto camino por donde deben caminar en conjunto, con su propia individualidad, entre todos y en esas dotes actuales que se han entregado". R. Espinoza y отros, "Realidad y actualidad..., 11. 
¿Qué debemos entender por ese carácter enigmático de la religación? Ya hemos visto que son las cosas las que vehiculan el poder de lo real que domina y nos apodera para impelernos a adoptar una forma de realidad en "la realidad" y por eso nuestra inteligencia en cuanto sentiente va diseñando las cosas reales (es su carácter técnico). Como señala Zubiri: "Tenemos que estar en la realidad, nos lo exigen las cosas reales en su realidad, pero ninguna es aquello en que se nos hace estar. Es el poder de lo real como enigma: estar en «la» realidad con las cosas reales. Es un poder enigmático" ${ }^{34}$. El carácter enigmático del poder de lo real lo experimenta todo ser humano haciendo su propia realidad personal, lo cual nunca acontece sin las cosas concretas. Es "esta" realidad de una cosa la que me exige adoptar una forma de realidad determinada, pero no es "la" realidad donde debo realizarme, el enigmatismo consiste en la interna articulación de ambos momentos que no son idénticos, pero paradójicamente no son separables. Así el poder de lo real nos lanza "hacia" lo que hace que nos realicemos, un fondo que se manifiesta como indecible y direccional. Aquí parece el otro elemento noológico fundamental en el último Zubiri, el elemento del "hacia" ${ }^{35}$. El "hacia" no es el "más" de la realidad como "de suyo en prius", sino que el "hacia" mienta

\footnotetext{
34 HD 103.
}

35 Véase, el estudio detallado del elemento noológico del "hacia": R. EsPINOzA, "Realidad y Hacia", en Realidad y ser..., 222-245. "La realidad no está aprehendida sentientemente tan solo como algo que está delante, sino que está también aprehendida en ese modo de sentir que es tenerla en hacia. No es un hacia extrínseco a la realidad, sino la realidad misma en dirección, la dirección como modo de realidad. Con lo cual el término de esta dirección es siempre algo problemático en principio: es justo la realidad allende la percepción. Ahora bien, estos distintos modos de presentársenos la realidad no están ni separados ni sumados, por así decirlo, sino que los unos recubren a los otros constituyendo una sola percepción de realidad. La percepción no es una síntesis de los sentidos, sino que los sentidos son los analizadores de la primaria y constitutiva unidad de la percepción. Y el «hacia» recubriendo los demás sentires es el «hacia» recubriendo las demás cualidades sensibles en su realidad inmediata, y, por tanto, lanzándonos en ellas mismas hacia lo real allende lo percibido". IRE 103. Y en HD Zubiri es muy explícito: "La impresión de realidad no es monopolio exclusivo de ningún sentir -del visual, por ejemplo- sino que abarca todos los sentires, incluso el de orientación y el del equilibrio. Por esto es por lo que la realidad no es solamente algo que está presente (como el caso de la vista) sino que tiene otros modos de estar. Uno de ellos es el «hacia». Y estos diversos modos no están simplemente yuxtapuestos sino intrínsecamente articulados... en una aprehensión de realidad. Todos los modos, en cuanto perforados por el «hacia», nos llevan desde sí mismos "hacia» algo allende 
la direccionalidad misma de la realidad. Es la realidad "en hacia” y por tanto indica el carácter mismo de búsqueda que mueve no solamente al hombre y lo dinamiza y lo realiza individual, social e históricamente, sino que indica el dinamismo propio de la realidad a secas. Los elementos noológicos del "más" y el "hacia" (junto al "de suyo" y al "prius") son fundamentales en la aprehensión primordial de la realidad de las cosas, de hecho, nuestro autor lo ejemplifica con la aprehensión, muy básica, por ejemplo, del verde real; en efecto, el verde real es "más" que mero verde ${ }^{36}$, por la fuerza de la realidad misma de aquel nos quedamos, también lanzados "hacia" la búsqueda de su realidad en profundidad; sin embargo en el caso de la realidad humana la cuestión es más grave, porque en dicha búsqueda está en juego nuestra propia realización de una forma u otra. El hombre es el único que experimenta el enigma del poder de lo real, y lo experimenta problemáticamente: "Como el poder de lo real es enigmático, este enigma imprime su carácter a la realización de nuestra realidad personal: es el problematismo de la fundamentalidad. Nos hacemos problemáticamente porque estamos fundados en un enigma, el enigma del poder de lo real" ${ }^{37}$.

El problematismo de la realidad enigmática en la cual lo deja el apoderamiento del poder de lo real, es para Zubiri un hecho innegable, el cual nos deja inquietos, situación que se manifiesta en las preguntas ineludibles de todo hombre: “¿Qué va a ser de mí?” y “¿qué voy a hacer de mí?”. La primera impone de inmediato una tarea, la de adoptar una forma de realidad que se presenta abierta a múltiples posibilidades.

lo inmediatamente aprehendido en los otros modos: el sonido hacia la cosa sonora, etc.". HD 164.

36 La realidad aprehendida en su nota de "más" apunta al carácter trascendental de la aprehensión. "Es un carácter que es interno a lo aprehendido. No nos saca de lo aprehendido, sino que nos sumerge en su realidad misma: es el carácter del «en propio», del "de suyo». Y es esta realidad la que de una manera que habrá que precisar inmediatamente, rebasa el contenido, pero dentro de la formalidad misma de alteridad. Este «rebasar» intraaprehensivo es justo la transcendentalidad. La impresión de realidad no es impresión de lo trascendente, sino impresión trascendental. El trans, no significa, por tanto, estar fuera o allende la aprehensión misma, sino estar "en la aprehensión», pero «rebasando» su determinado contenido. Dicho en otros términos. Lo aprehendido en impresión de realidad es, por ser real, y en tanto que realidad, «más» que lo que es como coloreado [...]". IRE 115.

37 HD 104. 


\section{CUERPO Y RELIGACIÓN}

El cuerpo como el "aquí" donde acontece la realidad, sentido y sentiente, se nos presenta en la aprehensión primordial de realidad como un "de suyo" reduplicativamente suyo, que debe hacer su propia realidad personal. Ese "aquí" es el elemento noológico propio del cuerpo. El hombre por su cuerpo está integrado al mundo, pero a la vez por el mismo cuerpo, en tanto corporeidad, trasciende el mundo ${ }^{38}$. Este momento de excedencia de nuestra realidad Diego Gracia lo explicita del siguiente modo: “[...] en esa actualización [como personeidad] mi realidad me está dada como extensa y tempórea y, por tanto como siendo más de lo inmediatamente aprehendido" 39 . La realidad humana es aprehendida como "más" que tal realidad, y le abre trascendentalmente al mundo. La refluencia del mundo sobre la personeidad constituye su ser, su Yo que se realiza optativamente. La realidad humana es una realidad absoluta pero relativa, absoluta porque es un "de suyo" que se sabe "suyo" pero su realidad personal debe ser cobrada a la realidad misma y lo hacemos apoderados por el poder de lo real, es lo que Zubiri llama el "hecho" de la religación, instalados en la realidad estamos bajo el dominio del poder de lo real.

El ser de la realidad humana es una "re-actualización" de su realidad nunca acabada, impelida por el poder de lo real. Lo que el hombre va realizando es su personalidad, ella "es la figura según la cual la forma de realidad se va modelando en sus actos, y en cuanto se va modelando en ellos" ${ }^{40}$. Se trata de una figura de intimidad, donde el hombre se va poseyendo a sí mismo en un carácter de autopropiedad, se realiza como más "suyo". La religación afecta a la figura de intimidad de la persona, tal como lo reclama Juan Bañón cuando se trata la religación se tiene poco en cuenta la dimensión figural de la persona ${ }^{41}$. La personalidad consiste en un despliegue figural:

38 “[...] a través de esto... finales de la obra zubiriana tenemos que la realidad «da de sí» su ser en la medida en que ella es radicalmente actual; esto es, se está presentando y se está presentando por el carácter de mero «estar»o mero ser real de ella misma en un «aquí». Y se está presentando por ser real en el mundo por ella abierto, un mundo cósmicamente «aquí» abierto en trascendencia dinámica; esto es, en una corporización que todo dinamiza. En el caso del hombre es un cuerpo que se subjetiva, social e históricamente". R. EsPinOZA y OTROs., "Realidad y actualidad...", 17.

40 HD 59.

41 J. Bañón, Metafísica y noología en Zubiri (Publicaciones Pontificia Universidad de Salamanca, Salamanca, 1999) 252. 
"En la figura que cada instante somos van envuelta incoactivamente muchas figuras distintas. En cada instante el hombre tiene la posibilidad constitutiva de desarrollar muy distintas personalidades. El hombre va eligiendo unas y dejando otras. Y lo que hace con todas esas personalidades es ser lo que puede con lo que es. Una personalidad que se va construyendo, destruyendo, modalizando y hasta reconstruyendo" ${ }^{\prime 2}$.

El poner atención en el carácter figural de la religación nos permite entender el carácter concreto de esta, no se trata de nada abstracto, es algo muy concreto, cada hombre va realizándose de modos diversos y por ende va teniendo figuras diversas. En cada acto ejecutado por el hombre su realidad se reactualiza en la intimidad del Yo, su corporeidad deviene en una nueva actualidad, "la figura y la configuración de la intimidad se va haciendo a lo largo del tiempo y de la vida" ${ }^{3}$, esto es lo que Zubiri llama personalidad. La realidad humana se va realizando optativamente a través de sus acciones. "El carácter de la realidad en las acciones es, pues, el ser apoyo para ser persona. Y este apoyo tiene un carácter muy preciso: consiste en ser el fundamento de la persona” ${ }^{44}$. La realidad se apodera de nosotros para ser relativamente absolutos, en esto consiste el hecho de la religación, es un hecho y no una teoría porque es aprehendido en la impresión de realidad en su carácter real mismo. El momento de realidad de toda cosa real, incluida la realidad humana, domina sobre su contenido, se presenta como un "prius" y un "más", modo como se presenta el poder de la realidad, que en el caso del hombre por ser una esencia abierta se presenta la realidad como la fundamentalidad con sus caracteres de ultimidad, posibilitancia e impelencia. La realidad tiene un carácter de fundamentalidad del ser personal del hombre, es el fundamento de su corporeidad, en tanto que "aquí". Si el cuerpo es el lugar de la realidad, su "aquî"; es allí donde acontece el poder de lo real. El cuerpo nos abre a la realidad fundamento, realidad donde estamos apoyados, posibilitados e impelidos para realizar nuestro propio ser. Religado al poder de lo real el hombre va haciendo probación de la realidad fundamento en la realización de su propio ser, esto significa que hay un proceso de maduración fundado en su apertura hacia la fundamentalidad. Se trata de un proceso de maduración comprensiva de la propia

42 SH 137.

$43 \mathrm{SH} 137$.

44 SH 64. 
realidad religada, esta cita nos permitirá entender de mejor modo el despliegue de maduración como un despliegue corporalizante:

"Incorporar significa, pues, en primer lugar, formar cuerpo, constituir en cierto modo la corporeidad de la actualización de lo real. Pero esto no es suficiente. Porque en segundo lugar, lo que corporaliza esta actualización es justamente la estructuración. Y para lograr inteligirla hemos tenido que ir a los momentos campal y mundanal distanciándonos en cierto modo de su estricto momento individual. Esta vuelta es lo que intelijo lo que la cosa era en su estructuración, esto es, intelijo cómo lo que era realmente constituye la estructuración misma de lo real. Pero entonces es claro que en lo que formalmente consiste el retorno mismo no es en el mero "volver» a lo real sino que es recuperar intelectivamente, desde lo que realmente la cosa es, su estructura y sus notas. $\mathrm{Y}$ en esto consiste la corporeidad de la actualización: es recuperación de la plenitud de lo real” ${ }^{35}$.

En este texto Zubiri es sumamente claro y, además, está en su línea noológica. El hombre religado a su realidad fundamento se ve obligado a realizar su ser personal optativamente construyendo un proyecto, construyendo lo real de modo técnico ${ }^{46}$. La realidad fundamento como posibilidad es algo "irreal" (en sentido zubiriano) y, por tanto, el hombre no puede configurar su intimidad más que pasando por el rodeo de la irrealidad ${ }^{47}$, debe por tanto haber un momento de distanciación del logos-razón de la aprehensión primordial de su propia realidad religada para la construcción de los esbozos de la realidad fundamento, ello requiere un sistema de referencia dados social e históricamente, y estos esbozos los probará experiencialmente incorporándolos de manera configurativa; he aquí el momento de refluencia hacia su realidad, la realidad queda a la luz de su ser cobrado a la realidad fundamento, donde la realidad ya "sida" queda incorporada a esta nueva actualidad. Maduración comprensiva es la recuperación nunca acabada de la pleni-

45 IRA 336.

46 Esto es fundamental en la investigación de nuestro Proyecto Fondecyt $\mathrm{N}^{\circ}$ 1140973: "Realidad y técnica en Zubiri”. Porque se ve la imbricación total entre lo real y la inteligencia en cuanto técnica para construir lo real desde sus caracteres lógicos a lo real mismo, pero esta función técnica de la inteligencia, que es propia para la existencia misma de la realidad humana, es en vistas también del carácter sentido mismo de ese enigma en tanto fundamentalidad que arrebata al hombre: su trascendentalidad.

47 Cfr. SH 141-142. 
tud de nuestra propia realidad. "El hombre se hace persona religado en su ser mismo [en su corporeidad] al poder de lo real en tanto que real, como último, posibilitante e impelente" ${ }^{48}$. En todo acto aprehensivo el hombre se actualiza como formal y reduplicativamente "de suyo", como realidad personal, la persona no es ninguna sustancia sino solo la actualización del aprehensor en la aprehensión misma, pues bien, actualizando el hombre su realidad se le da como "más" de lo aprehendido, es la realidad misma la que le fuerza bajo el apoderamiento del poder de lo real "hacia" la búsqueda de su fundamento. Por el hecho inexorable de la religación, todo hombre tiene una voluntad de verdad real, voluntad de una o de otra manera de asentar su ser, aunque sea en sí mismo, como es el caso del ateo. De acuerdo a Zubiri esa voluntad de verdad se despliega en un acto que tiene dos aspectos, uno es inteligir qué sea esa realidad fundamento, y otro acceder a aquella realidad fundamento apropiándose de ella, en tanto verdadera, en la constitución de su ser personal, apropiándose esa realidad personal. Vemos así que el proceso intelectivo humano y la propia actualización de su ser personal, de su Yo, están íntimamente unidos.

En la aprehensión primordial de realidad por sentir cenestésico el hombre se aprehende a sí mismo como realidad en intimidad (es el carácter más propio de la realidad humana como "de suyo"), allí está la personeidad con toda la riqueza de sus notas, pero aún no desplegadas. Su despliegue acontece por el hecho de la religación, es ella el fundamento del proceso de personalización primero proyectiva y luego actualizada en la propia realidad. Los esbozos que se insertan probándose en la propia construcción de la persona son los de la realidad fundamento de allí que:

"En su entrega intelectiva, el hombre descubre que su ser es formal y constitutivamente experiencia de Dios. Ser persona humana es una manera de ser experiencia de Dios, a saber, experiencia tensiva. Una experiencia que se despliega individual, social e históricamente. Ser hombre es una manera finita de ser Dios" ${ }^{\prime 9}$.

El hombre como experiencia de Dios es ese momento de reversión comprensiva donde su realidad personal queda a la luz de su ser, es el encuentro entre lo que ha decidido ser y lo que está siendo, recordemos que el hombre en tanto realidad personal es siempre "el mismo" pero

48 HD 585.

49 HD 586. 
nunca "lo mismo". El autor de una acción, por la libertad y la responsabilidad que implica, es mucho más que un productor ocasional de una acción, es constructor de su vida, y el cuerpo humano entendido como soma manifiesta de manera plena al hombre como autor de ella ${ }^{50}$. Soma es el modo de comprender el cuerpo humano para el último Zubiri, el cuerpo como el "aquî"51 donde se manifiesta la verdad de todo hombre, "un cuerpo de verdad" 52 impelido y posibilitado por el hecho inexorable de la religación.

50 Pedro Laín Entralgo respecto al conocimiento del cuerpo humano dice: "solo cuando refiera al autor de sí mismo los actos y las acciones con que su condición de agente y actor se realiza, solo entonces podemos decir que real y verdaderamente hemos conocido lo que es un cuerpo humano". P. Laín EnTRALGo, El cuerpo humano. Teoría actual (Espasa. Calpe, Madrid, 1991) 234. Los puntos de encuentro de la visión del cuerpo en Zubiri y Laín Entralgo, la encontramos en: J. Ayala, "El monismo «integrable» de Xavier Zubiri y Pedro Laín Entralgo", en The Xavier Zubiri Review 1 (1998) 49-56.

51 "El «estar» físico del hombre mismo es, a una, un «estar» que actúa en actualidad tanto en el "aquí» del cosmos como en la mera y simple realidad que es en el mundo. Y ese carácter talitativo del cuerpo humano como "estar aquí» se abre trascendentalmente, en «más», a la inespecificidad del mundo. El cuerpo humano es un «aquí» en apertura, en "más», y esto es lo que no vio el análisis existencial del Dasein del primer Heidegger; de allí que el cuerpo sea anterior a cualquier tipo de organización de él mismo e incluso de cualquier tipo de subjetivación”. R. EsPINOZA Y OTROS, "Realidad y actualidad...", 8.

52 "La idea de llamar «soma» a la plena actualidad física del cuerpo humana vino a la mente de Zubiri, por lo que de él oí más de una vez, considerando el sentido de esa palabra griega en un texto de San Ignacio de Antioquía. Para un griego cualquiera, el sentido normal y fuerte del término soma era ni más ni menos el que para nosotros posee el término cuerpo; pero el autor cristiano quiere utilizarlo para llamar: soma tes alétheias "cuerpo de la verdad", al conjunto sistemático de las verdades que constituyen el todo de la fe cristiana, esto es, al sistema de las varias proposiciones verbales en que el todo de esa fe se manifiesta a quien ha de profesarla. Así entendida, la palabra soma no es simplemente la traducción griega del "cuerpo" de la lengua española, el body de la inglesa y el Leib de la alemana; para el cristiano "cuerpo» como oposición al "alma». He podido ver que, en un sentido no religioso, sino estrictamente profano, Aristóteles llama soma tes pisteos, «cuerpo de la confianza» o "de la creencia» ([Ret. 1354 a 16]), al conjunto de las pruebas que hacen convincentes una demostración. Soma en definitiva, es ahora el conjunto unitario de las notas en que se hace manifiesta y presente la esencia de algo". P. Laín EnTralgo, El cuerpo humano..., 232. Zubiri le entrega la autoría a la afirmación "cuerpo de la verdad"

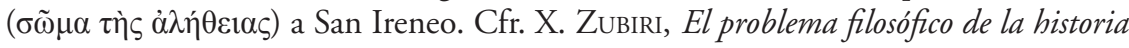
de las religiones (PFHR), (Alianza, Madrid, 1993) 267. 


\section{CONCLUSIÓN}

Nos gustaría en esta conclusión indicar algunos rasgos de esta corporización de la dimensión teologal de la religación en la religión cristiana. La religión es la plasmación de la religación, su cuerpo; el cual conlleva una visión concreta de Dios, el hombre y el mundo, como se concretiza de modo experiencial a modo de tanteo, admite muchas formas, es lo que para Zubiri constituye la historia de las religiones, dentro de ellas el Cristianismo: "[...] el cristianismo no es solo religión verdadera en sí misma, sino que es la verdad, «radical», pero además «formal», de todas las religiones. Es, a mi modo de ver, la trascendencia no solo histórica, sino teologal del cristianismo. La experiencia teologal de la humanidad es así la experiencia de la deiformidad en su triple dimensión individual, social e histórica: es cristianismo en tanteo" 53 .

La afirmación del Cristianismo como "la religión verdadera" no se sustenta en una declaración apologética (ni menos soberbia o peyorativa con otras religiones), bajo estructuras argumentativas intrínsecas, tantas veces asumida por la historia del Cristianismo, su justificación radica en la dimensión teologal del hombre y el hecho inexorable de la religación en ella y en esto el cuerpo mismo es fundamental; por ello Dios se encuentra manifiesto a todo hombre, en toda situación individual, social e histórica y en toda religión. Lo que ha querido Dios, gratuitamente, es la plasmación ad-extra de su propia vida trinitaria, para ello ha construido la creación como su lugar (la Naturaleza), y dentro de ella, acontece un lugar privilegiado; el cuerpo del hombre donde debiese resplandecer su verdad, el cuerpo humano es el "aquí". En tal "aquí" acontece la intimidad de la co-corporeidad manifiesta individual, social e históricamente y la verdad del hombre y Dios; siempre con el carácter de novedad, por ello se da en una continua corporización:

"En virtud de la adhesión y de la entrega personal a Cristo, el hombre adquiere la corporeidad misma de este. Corporeidad no tiene aquí un significado físico en el sentido de "carne». Todo antiguo distinguía entre $\sigma \omega ́ \mu \alpha$ y $\sigma \alpha \rho \xi$, entre cuerpo y carne [...]. El $\sigma \omega ́ \mu \alpha$ en cuanto tal tiene dos caracteres que aquí nos importa subrayar. En primer lugar la presencia física de algo. Y, en segundo lugar su consistencia interna propia. Pues bien, por su entrega personal a Dios, cada uno de los creyentes en Cristo tiene una corporeidad en el sentido de una

53 HD 15. 
presencia y de una consistencia. El hombre queda en Dios, con la corporeidad misma de Dios" ${ }^{\prime 4}$.

Volvemos finalmente al cuerpo como ese "aquî" noológico espaciotemporal originario, anterior a las organizaciones, a todo tipo de rutas establecidas, donde Dios y el hombre somáticamente pueden acontecer. Zubiri diría simplemente que se actualicen, se actualicen en el cosmos como mero "aquí", que acontezcan como "aquî" somáticos. Nuestro autor lo deja claro, el cuerpo es radicalmente soma, actualidad y, por eso, luego se articula en una trama de puntos solidaria que finalmente se organiza (es el logos y la razón). De allí luego todo tipo de estructuración, la que sea, pero ulterior al cuerpo en su mero manifestarse expresivo. No está demás indicar que en el ámbito de una topología nos movemos en la superficie desde el acontecer en su "aquí". En el sentir mismo del cuerpo, lo que se siente es que este es puro darse físico somático en un aquí cósmico abierto al mundo, pero es en el logos donde todo comienza a generar ciertos niveles de afirmación que generan tramas funcionales y solidarios de momentos; en esto ya estamos en el carácter del espacio y su exterioridad en el lenguaje, por ello hemos podido decir algo acerca del cuerpo y la religación. Es la lectura final que hacemos de este texto temprano de nuestro autor:

"Dios es la luz que sin división ni distinción ni circunscripción, se halla presente en el topos entero. A su vez, el modo de presencia de las cosas en el «lugar», es decir su realidad, se llamó por los griegos $\sigma \tilde{\omega} \mu \alpha$, cuerpo [...]. La articulación de la luz y de la corporeidad, explica y expresa, pues, la articulación metafísica entre la realidad y su fuente divina. Desde Dios, la emanación es luminiscencia, refluencia. Pero luminiscencia agente. La luz se expande produciendo y constituyendo el «lugar»: y en esta expansión lo creado cobra su realidad, su corporeidad, su ser" ${ }^{25}$. 